\title{
Mechanisms of oil displacement by ASP-foam and its influencing factors
}

\author{
Wu Wenxiang*, Pan Jianhua and Guo Mingri \\ Key Laboratory of Enhanced Oil and Gas Recovery, Ministry of Education, Daqing Petroleum Institute, Daqing, \\ Heilongjiang 163318, China \\ (C) China University of Petroleum (Beijing) and Springer-Verlag Berlin Heidelberg 2010
}

\begin{abstract}
ASP-foam (ASPF) is a system prepared by injecting natural gas into the conventional alkalisurfactant-polymer (ASP) system. Foam can be formed in the porous media by the interaction of gas and surfactant in the ASP system. With the ASPF system, oil recovery is improved as the interfacial tension (IFT) is reduced to a relatively low level, and the swept volume is enlarged. In this paper, four surfactants were evaluated and characterized by IFT between ASP system and oil and the foaming performance. Alkyl benzene sulfonate (ORS-41) was chosen as the surfactant to best reduce IFT between displacement fluids and oil and improve the foaming performance. The mechanisms of ASPF flooding were studied in this paper, the results show that the ASPF flooding not only enlarges the swept volume but also enhances the displacement efficiency. The effects of reservoir heterogeneity, the gas-liquid ratio of ASPF system, and the concentrations of polymer and surfactant on the displacement efficiency were studied. A field trial of ASPF flooding has also been conducted. Both the laboratory results and the field trial results show that the ASPF flooding can significantly increase the oil recovery, with a 30\% increase in the proportion of the original oil in place recovered compared with water flooding.
\end{abstract}

Key words: Oil displacement by ASPF system, oil displacement mechanism, displacement efficiency, influencing factor

\section{Introduction}

After 40 years of development, Daqing Oilfield has entered an extremely high water-cut stage, and it becomes more and more difficult to stabilize the oil production of the oilfield. For this reason, many new enhanced oil recovery (EOR) techniques have been developed and one of them is alkali-surfactant-polymer (ASP) flooding. The primary mechanism of ASP flooding is to increase the oil displacement efficiency (Liu et al, 2007), and the secondary mechanism is to enlarge slightly the swept volume. ASP flooding is estimated to increase the oil recovery by $20 \%$ (Wang and Cheng, 2003). Both laboratory experiments and a field trial show that the residual oil exists in the low permeability layers in the upper part of the strata after ASP flooding ( $\mathrm{Li}$ et al, 2005). However, in the ASP flood process, the macromolecular chemicals hardly enter the micro pore spaces, thus the residual oil trapped in these pore spaces would not be swept out. The foam flooding can enlarge swept volume, especially in a positive rhythmic reservoir with serious heterogeneity, but its displacement efficiency is relatively low (Li et al, 2006; Li et al, 2008; Liu et al, 2008). So ASP-foam (ASPF) flooding was developed as a new

*Corresponding author. email: sygcwuwenxiang@sina.com Received November 28, 2008
EOR technique, combining foam flooding and ASP flooding. Consisting of alkali, surfactant, polymer, and gas, the ASPF system not only greatly increases displacement efficiency, but also flows into the low permeability layers, and then greatly enlarges the swept volume (Zhao et al, 2004).

\section{Properties evaluation of ASPF system}

The polymer used in all experiments was polyacrylamide $1275 \mathrm{~A}$, with a molecular weight of $2.5 \times 10^{7}$. The alkali was sodium hydroxide. The surfactants were alkyl benzene sulfonate (ORS-41), $\alpha$-alkene sulfonate (DQ), plant carboxylates $(\mathrm{CX})$, and non-ionic surfactant (NOS). Gasliquid ratio was $1: 1$.

The water used to saturated cores was simulated formation water with a salinity of $6,778 \mathrm{mg} / \mathrm{L}$ and the water produced in the Daqing Oilfield was used to prepare the flooding systems.

\subsection{Experimental methods}

The interfacial tension (IFT) between ASP solution and oil was measured with a Texas-500 spinning drop interfacial tensiometer (Temco, Inc., American), with an accuracy of $10^{-6}$ $\mathrm{mN} / \mathrm{m}$.

A comprehensive foam index was proposed to evaluate the foaming properties of the ASP-foam system and can be expressed as a function of foam height and half-life. 


$$
F=S=\int_{t_{0}}^{t_{0}+t_{1 / 2}} f(t) \mathrm{d} t
$$

where $f(t)$ is defined as the foam height as a function of time; $t_{0}$ is the time that the foam reached its maximum foam height; $t_{1 / 2}$ is the time required for the foam to collapse to half of its initial value.

A specified volume of ASP solution was added into a glass tube, and then natural gas was pumped into the tube from the bottom at a constant flow rate of $2-3 \mathrm{~mL} / \mathrm{min}$ to generate foam. The foam height was monitored and recorded with time. The variation of foam height with time was plotted and then the comprehensive foam index was calculated. The schematic diagram of the measurement of foaming properties is shown in Fig. 1.

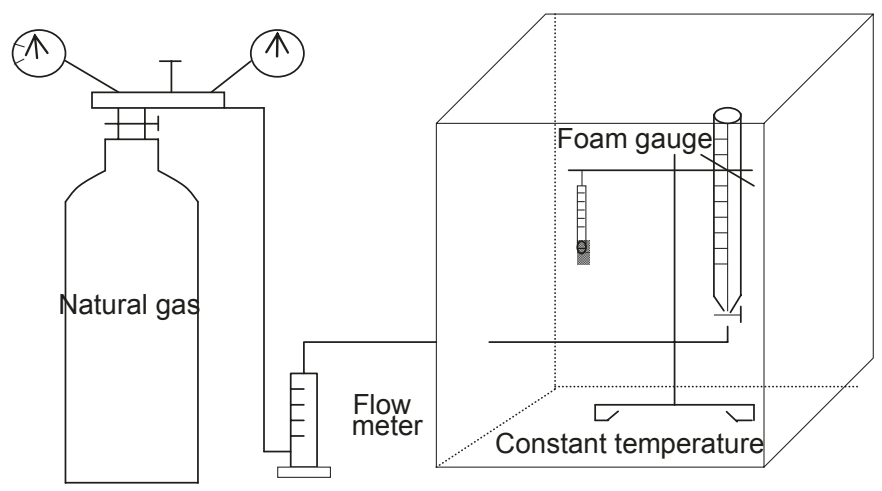

Fig. 1 A system for measuring the foaming properties of foaming solution

\subsection{Results and discussion}

In order to greatly improve the oil recovery, the oil displacement efficiency should be increased and the swept volume should be enlarged. The surfactant in the ASPF system would not only greatly reduce the interfacial tension of oil-water system to a ultra-low value, thus increasing the displacement efficiency, but also enhance foaming properties (foaming ability and foam stability). However, commonlyused foaming agents would not efficiently reduce interfacial tension between oil and displacement fluids. A surfactant which not only reduces the interfacial tension but also has strong foaming capacity was selected by measuring the interfacial tension and foaming properties of four types of surfactants.

Table 1 summarizes the experimental results of interfacial tension between the Daqing crude oil and the ASP systems. As a result, ultra-low interfacial tension, on the order of $10^{-3}$ $\mathrm{mN} / \mathrm{m}$, between the Daqing crude oil and the ASP systems was achieved by adding alkyl benzene sulfonate (ORS41), $\alpha$-alkene sulfonate (DQ), plant carboxylates (CX), or non-ionic surfactant (NOS), respectively. This can meet the demand for the interfacial tension level of the ASPF system. From Table 1, it can be seen that the comprehensive foam index of ASPF systems containing ORS-41 or DQ were relatively higher than the other two systems. ORS-41 is commercially available and the interfacial tension between the ASP solution containing ORS-41 and the Daqing crude oil was low, so ORS-41 was selected as the surfactant for the subsequent studies of oil displacement and its influencing factors.

Table 1 Interfacial tension between ASP solutions and oil and the comprehensive foam index of ASPF systems

\begin{tabular}{cccc}
\hline Surfactant & $\begin{array}{c}\text { surfactant } \\
\text { concentration } \\
\text { wt } \%\end{array}$ & $\begin{array}{c}\text { Minimum interfacial tension } \\
\mathrm{mN} / \mathrm{m}\end{array}$ & $\begin{array}{c}\text { Comprehensive } \\
\text { foam index }\end{array}$ \\
\hline $\mathrm{CX}$ & 0.30 & $8.5 \times 10^{-3}$ & 7570 \\
$\mathrm{DQ}$ & 0.30 & $6.0 \times 10^{-3}$ & 8060 \\
NOS & 0.30 & $7.5 \times 10^{-3}$ & 5005 \\
ORS-41 & 0.30 & $3.5 \times 10^{-3}$ & 9650 \\
\hline Notes: Polymer concentration $, 1,200 \mathrm{mg} / \mathrm{L} ; \mathrm{NaOH}$ concentration, $1.2 \mathrm{wt} \%$
\end{tabular}

Notes: Polymer concentration, 1,200mg/L; NaOH concentration, $1.2 \mathrm{wt} \%$

\section{Macroscopic mechanisms of oil displacement by ASPF system}

In the following experiments, the ASP solution was composed of $1,200 \mathrm{mg} / \mathrm{L}$ polyacrylamide $1275 \mathrm{~A}, 1.2 \mathrm{wt} \%$ $\mathrm{NaOH}$, and $0.3 \mathrm{wt} \%$ ORS-41. The water used to saturated core samples was simulated formation water with a salinity of $6,778 \mathrm{mg} / \mathrm{L}$; and water produced in the Daqing Oilfield was used to prepare the ASPF system and to flood the core samples (water flooding and follow-up water flooding). The gas-liquid ratio was 1:1.

1) The foam preferentially forms in and plugs macropores in reservoirs, thereby reducing their permeability and diverting subsequently injected fluids into low-permeability zones to improve the oil recovery in low permeability zones.

Four core samples $(10 \mathrm{~cm}$ in length and $2.5 \mathrm{~cm}$ in diameter) were used to study this displacement mechanism. Experimental procedures are as follows: (1) The core was evacuated for $3.5 \mathrm{~h}$, and then was saturated with simulated formation water of a salinity of $6,778 \mathrm{mg} / \mathrm{L}$ to measure its porosity. (2) The water saturated core was then kept in a thermostat $\left(45^{\circ} \mathrm{C}\right)$ for over $12 \mathrm{~h}$. (3) Water was injected into the core at a rate of $6 \mathrm{~mL} / \mathrm{h}$ until the injection pressure stabilized. (4) ASPF displacement system was injected into the core at a rate of $6 \mathrm{~mL} / \mathrm{h}$ until the injection pressure stabilized, and then the resistance factor was calculated. (5) The core was flooded by water at a rate of $6 \mathrm{~mL} / \mathrm{h}$ until the injection pressure stabilized, and then the residual resistance factor was calculated.

Fig. 2 shows a plot of the resistance factor versus permeability for the ASPF system. This indicated that the higher the permeability of the cores, the higher the resistance factor when the foam flowed in the cores under experimental conditions, that is to say, the blocking ability of foam in the high permeability cores is much higher than it in the low permeability ones. The foam selectively plugs macropores rather than the micropores. 


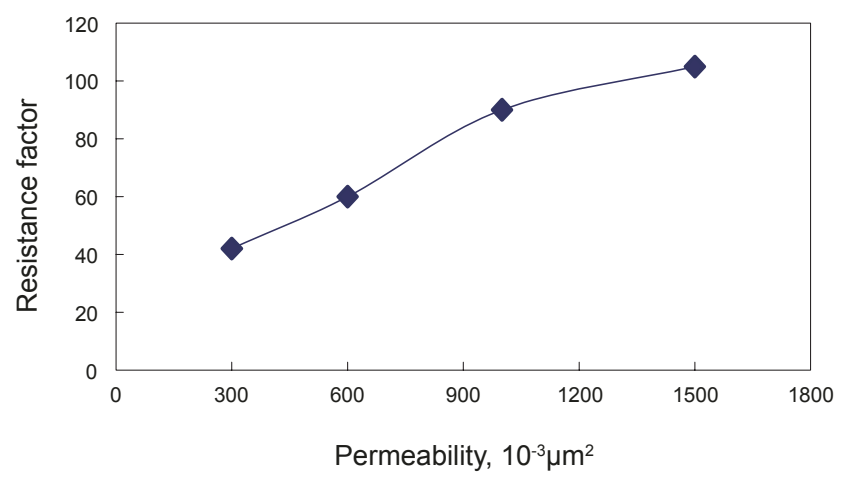

Fig. 2 The resistance factor versus the permeability

2) The foam has the ability of "plugging the water channel rather than flow path for oil". The foam is used to selectively modify injection profiles, and thus enhancing the oil recovery of the oil-bearing layers.

Three cylindrical core samples $(2.5 \mathrm{~cm}$ in diameter and $10 \mathrm{~cm}$ in length) with different permeabilities were selected to test ASPF system for profile control. After air evacuation, the core was saturated with water, and then saturated with crude oil to irreducible water saturation. Afterwards the ASP solution and natural gas were simultaneously injected into the core. When the foam was observed at the exit end of the core, the productions of fluid, oil and gas were simultaneously recorded.

Laboratory flooding experiments (Table 2) showed that the foam formation was closely related to the permeability and oil saturation of the cores. Effective foam would not be generated when the oil saturation was more than $30 \%$. In the high permeability cores, the foam was generated at relatively high oil saturation (15\%); but in the low permeability cores, foam was only generated at low oil saturation ( $8 \%)$ and the foam was observed at the outlet after a large amount of ASPF (about 16.7 pore volumes $(\mathrm{PV})$ ) was injected into the core. This means that the foam is unstable when the oil exists and in low permeability layers foam is formed only when the oil saturation is low. Therefore, the foam has the characteristic of "blocking the water channel rather than flow path for oil" and "blocking the high permeability zones rather than the low ones."

Table 2 Three ASPF flooding experiments in cores with different permeabilities

\begin{tabular}{cccccc}
\hline Core sample & $\begin{array}{c}\text { Core permeability } \\
K, \mathrm{mD}\end{array}$ & $\begin{array}{c}\text { Initial oil saturation } \\
S_{\mathrm{oi}}, \%\end{array}$ & $\begin{array}{c}\text { Oil saturation after } \\
\text { water flooding } S_{\mathrm{wr}} \%\end{array}$ & $\begin{array}{c}\text { Residual oil } \\
\text { saturation } S_{\text {or }, \%} \%\end{array}$ & $\begin{array}{c}\text { Injection } \\
\text { volume, PV }\end{array}$ \\
\hline $703-7$ & 372 & 70.6 & 33.0 & 8 & 16.7 \\
E-8 & 2190 & 71.9 & 32.5 & 13 & 9.75 \\
$6-30$ & 3300 & 72.0 & 32.1 & 15 & 6.0 \\
\hline
\end{tabular}

3) The gas in ASPF flood can ascend and displace the residual oil in the top layer. It has the advantage in enhancing the oil recovery of low permeability layers.

The oil displacement experiments were carried out with a visual sand pack $(40 \mathrm{~mm} \times 40 \mathrm{~mm})$. Experimental apparatus is schematically illustrated in Fig. 3.

The simulated oil used in experiments was prepared by blending kerosene and well-head oil from the Daqing Oilfield. The viscosity of the simulated oil is $10 \mathrm{mPa} \cdot \mathrm{s}$ (at 45 ${ }^{\circ} \mathrm{C}$ ). Experimental procedures are as follows: (1) Evacuate the sand pack for $3.5 \mathrm{~h}$, and saturate the model with simulated formation water (of salinity of $6,778 \mathrm{mg} / \mathrm{L}$ ), and then measure its porosity. (2) Keep the water saturated model in a thermostat at $45{ }^{\circ} \mathrm{C}$ for over $12 \mathrm{~h}$. (3) Inject simulated oil into the model until no water flows out, and then determine the initial oil saturation. (4) Inject water into the model at a specified rate until the water cut exceeds $98 \%$; then calculate the water displacement oil recovery. (5) Inject ASPF system. (6) After the ASPF slug is injected, continue to inject water into the model until the water cut reaches $98 \%$, and then calculate the oil recovery of the ASPF flooding. In the flooding experiments, images of displacement process were collected and digitized with an image acquisition system (shown in Fig. 4), and the characteristics of the microscopic oil displacement was studied by image analysis.

A comparison was made between water flooding and
ASPF flooding in visual sand packs that consisted of fine sand overlying coarse sand. In water flooding experiment, the water preferentially flowed into and advanced quickly along the high permeability layers. Most of the injected water flowed along the high permeability layers and could not sweep the oil in the low permeability ones, as shown in Fig. 4(a) and Fig. 4(b), so the oil recovery by water flooding was low. In the ASPF experiment, the injected fluids primarily entered into the high permeability layers and almost all of oil in these layers was displaced from the model, as more fluids were injected into the model most of the oil in the low permeability layers was swept out because of the buoyancy of the added gas after the foam was broken. The enhanced oil recovery by the gas buoyancy in ASPF flooding was more significant.

4) The ultra-low interfacial tension of the ASPF system plays an important role in enhancing displacement efficiency.

A comparison was made between Fig. 4(a) and Fig. 4(c). For the water-flooded cores the swept volume and the displacement efficiency in the swept zone were all very low. However, for the ASPF flooded cores, the displacement efficiency in the lower half of the core was very high because ASP has an ultra-low interfacial tension with oil. Because of the buoyancy of the added gas, the low permeability layers in the upper half of the core unswept by the initial water flooding, was swept by ASPF flooding. 


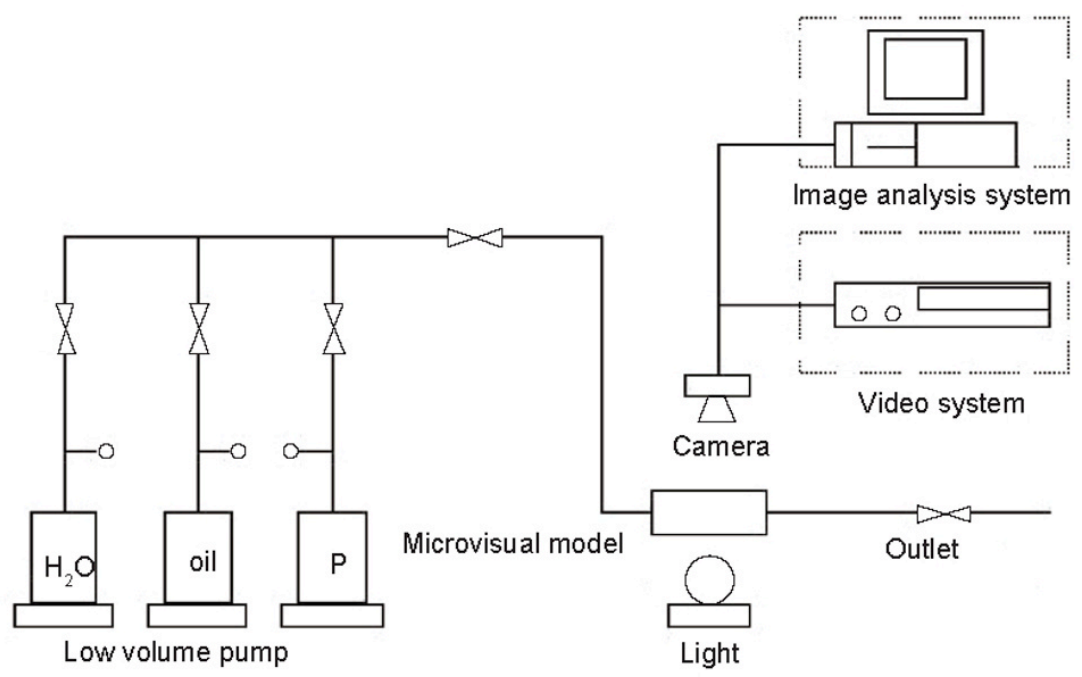

Fig. 3 The schematic diagram of microscopic oil displacem ent experiment

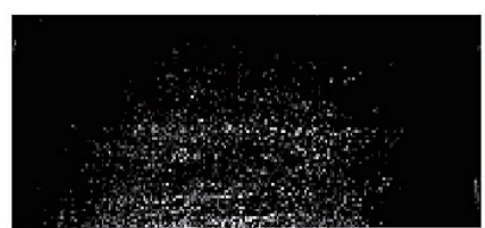

(a) Visual sand pack saturated with oil

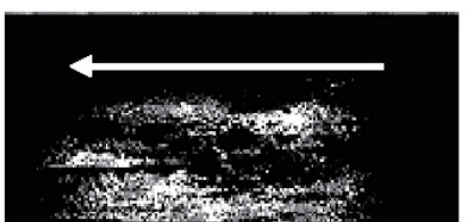

(b) Visual sand pack after water flooding

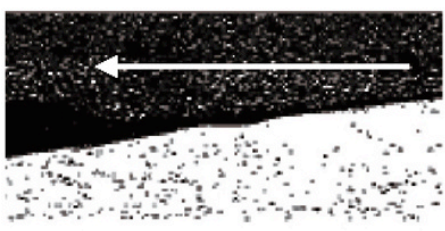

(c) Visual sand pack after ASPF flooding

Fig. 4 Laboratory findings of visual models filled with fine sand overlying coarse sand

\section{Factors affecting the performance of ASPF flooding}

\subsection{Experimental}

The cores used to evaluate the performance of ASPF flooding were $4.5 \mathrm{~cm} \times 4.5 \mathrm{~cm} \times 30 \mathrm{~cm}$, and their permeabilities and permeability variation factors are listed in Table 3 . The simulated oil was prepared by mixing kerosene and well-head oil from the Daqing Oilfield and its viscosity is $10 \mathrm{mPa} \cdot \mathrm{s}$.

ASP solution was composed of polyacrylamide $12275 \mathrm{~A}$, $\mathrm{NaOH}$, and ORS-41. Simulated formation water with a salinity of $6,778 \mathrm{mg} / \mathrm{L}$ was used to saturate the cores, and the water produced in the Daqing Oilfield was used in water flooding, follow-up water flooding and to prepare the flooding system of foam.

Experimental procedure was as follows: (1) After evacuation for $3.5 \mathrm{~h}$, the model was saturated with simulated formation water to measure its porosity. (2) The water saturated model was put into a thermostat at $45^{\circ} \mathrm{C}$ for over $12 \mathrm{~h}$. (3) Oil was injected into the model at a rate of $20 \mathrm{~mL} /$ $h$ until there was no water flowing out. Then the initial oil saturation was calculated. (4) The model was then flooded by water with a specified flow rate of $20 \mathrm{~mL} / \mathrm{h}$ until the water cut reached $98 \%$. The water displacement recovery was calculated. (5) An ASPF slug was injected. (6) Water continued to be injected into the model until the water cut reached $98 \%$, and the oil recovery by the ASPF flooding was then calculated.

\subsection{Results and discussion}

\subsubsection{Effect of reservoir heterogeneity}

Experimental results (listed in Table 3 ) indicated that when the gas-liquid ratio was specified, the higher the permeability variation factor, the higher the incremental oil recovery by ASP-foam flooding over water flooding, and the higher the final recovery ratio. The incremental oil recovery ratio reached its highest value when the permeability variation factor was 0.72 , but the final recovery ratio by ASP-foam flooding decreased when the permeability variation factor was 0.8 . This means the foam is selectively sensitive to reservoir heterogeneity. In the physical models with permeability variation factor of 0.72 , the foam would not only control the injection profiles but also reduce gaseous phase mobility, thereby enhancing the conformance efficiency and then the oil recovery. 
Table 3 Physical experimental results of ASPF flooding

\begin{tabular}{|c|c|c|c|c|c|c|c|c|}
\hline Test & $\begin{array}{c}\text { Water } \\
\text { permeability } \\
K_{\mathrm{w}}, \mathrm{mD}\end{array}$ & $\begin{array}{l}\text { Permeability } \\
\text { variation factor }\end{array}$ & $\begin{array}{l}\text { Gas-liquid } \\
\text { ratio }\end{array}$ & $\begin{array}{c}\text { Initial oil } \\
\text { saturation } \\
\quad S_{\mathrm{oi}}, \%\end{array}$ & $\begin{array}{c}\text { Oil recovery by } \\
\text { water flooding } \\
\eta_{\mathrm{w}}, \%\end{array}$ & $\begin{array}{l}\text { Incremental oil } \\
\text { recovery by ASPF } \\
\text { flooding, } \%\end{array}$ & $\begin{array}{l}\text { Total oil } \\
\text { recovery, } \%\end{array}$ & $\begin{array}{c}\text { Recovery over ASP } \\
\text { flooding } \Delta \eta, \%\end{array}$ \\
\hline 1 & 484 & - & - & 69.3 & 40.6 & 14.8 & 55.4 & - \\
\hline 2 & 420 & 0.50 & $1: 1$ & 68.6 & 36.8 & 25.4 & 62.2 & 9.6 \\
\hline 3 & 772 & 0.60 & $1: 1$ & 66.0 & 40.4 & 25.8 & 66.2 & 10.2 \\
\hline 4 & 601 & 0.60 & $2: 1$ & 70.8 & 39.6 & 26.2 & 65.8 & 10.4 \\
\hline 5 & 482 & 0.60 & $3: 1$ & 69.0 & 39.2 & 27.6 & 66.8 & 11.4 \\
\hline 6 & 577 & 0.72 & $1: 1$ & 66.9 & 39.0 & 28.0 & 67.0 & 11.6 \\
\hline 7 & 520 & 0.72 & $2: 1$ & 67.6 & 38.8 & 29.3 & 68.1 & 12.7 \\
\hline 8 & 598 & 0.72 & $3: 1$ & 70.5 & 39.2 & 30.6 & 69.8 & 14.4 \\
\hline 9 & 622 & 0.72 & $4: 1$ & 68.8 & 38.4 & 30.2 & 68.6 & 13.2 \\
\hline 10 & 760 & 0.72 & $5: 1$ & 67.7 & 39.1 & 26.7 & 65.8 & 10.4 \\
\hline 11 & 548 & 0.80 & $1: 1$ & 63.0 & 39.3 & 22.5 & 61.8 & 6.4 \\
\hline 12 & 573 & 0.80 & $3: 1$ & 63.3 & 38.1 & 25.8 & 63.9 & 8.5 \\
\hline
\end{tabular}

Notes: ASP displacing fluid. Polymer: 1275A, 1,200 mg/L; Alkali: NaOH, 1.2wt\%; Surfactant: ORS-41, 0.3wt $\%$

\subsubsection{Effect of gas-liquid ratio}

Fig. 5 shows the ASPF flooding results when permeability variation factor was 0.72 . The oil recovery by ASPF flooding increased with the gas-liquid ratio, and reached the maximum value when the gas-liquid ratio was 3:1; after that the oil recovery decreased with an increase in gasliquid ratio. During the experiment there was a big oil strip enriched at the delivery end of the model when the gas-liquid ratio was $3: 1$; the oil strip changed into "oil foam" while the gas-liquid ratio was $4: 1$ or $5: 1$. This means that there was an optimized gas-liquid ratio in the ASPF system, under which the foam produced by ASPF system can effectively control the mobility of fluids in medium, thereby enlarging the swept volume.

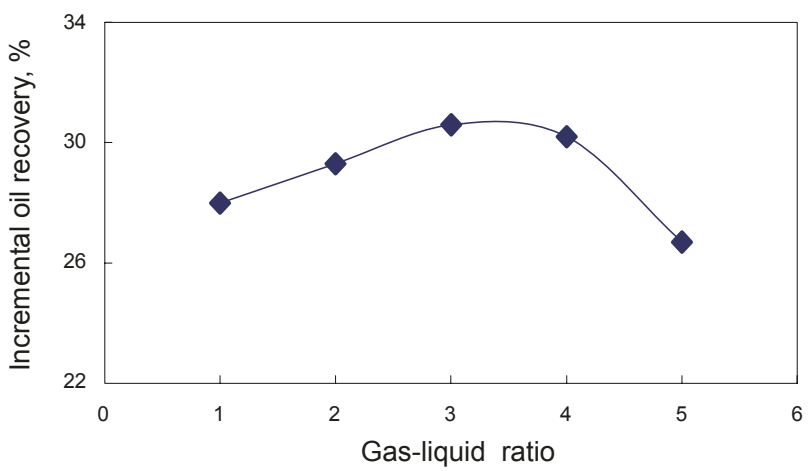

Fig. 5 The influence of gas-liquid ratio on oil recovery

\subsubsection{Effect of polymer concentration}

The effect of polymer concentration on the displacement efficiency was evaluated when the concentrations of surfactant and alkali were fixed at $0.3 \mathrm{wt} \%$ and $1.2 \mathrm{wt} \%$, respectively, and the experimental results are shown in Table 4. The oil recovery increased markedly with an increase in the polymer concentration in the ASPF system. This means that with an increase in the polymer concentration the viscosity of the system increased, thus improving the injection profiles; on the other hand, the foam-water (or foam-oil) interface was strengthened by adding more polymers, thus increasing the stability of the system.

\subsubsection{Effect of surfactant concentration}

Table 5 shows experimental results of the influence of surfactant concentration on the recovery ratio in artificial heterogeneous cores with a permeability variation factor of 0.72 . The formulation of alkaline-surfactant-polymer displacing fluid was listed in Table 5 . The recovery ratio increased from $25.3 \%$ to $30.3 \%$ when the surfactant concentration increased from $0.1 \mathrm{wt} \%$ to $0.3 \mathrm{wt} \%$, with an increment of $5.0 \%$. However, the recovery ratio increased to $31.0 \%$ when the surfactant concentration was $0.5 \mathrm{wt} \%$, with an increment of only $0.3 \%$; and the recovery ratio increased by only $0.2 \%$ when the surfactant concentration increased from $0.5 \mathrm{wt} \%$ to $1.0 \mathrm{wt} \%$.

The experimental results discussed above indicate that the optimized ASPF system would significantly enhance the oil recovery, with the incremental oil recovery ranging as high as an extra $30 \%$ of the original oil in place compared to water flooding. 
Table 4 The effect of polymer concentration on the oil recovery by ASPF flooding

\begin{tabular}{|c|c|c|c|c|c|}
\hline Test & $\begin{array}{l}\text { Gas-liquid } \\
\text { ratio }\end{array}$ & $\begin{array}{l}\text { Size of the } \\
\text { slug, PV }\end{array}$ & $\begin{array}{l}\text { Polymer concentration in } \\
\text { the main slug, } \mathrm{mg} / \mathrm{L}\end{array}$ & $\begin{array}{l}\text { Incremental oil } \\
\text { recovery, } \%\end{array}$ & $\begin{array}{c}\text { Total oil } \\
\text { recovery, \% }\end{array}$ \\
\hline 1 & $1: 1$ & 0.35 & 100 & 16.73 & 49.79 \\
\hline 2 & $1: 1$ & 0.35 & 500 & 23.00 & 57.24 \\
\hline 3 & $1: 1$ & 0.35 & 1200 & 30.00 & 63.00 \\
\hline 4 & $1: 1$ & 0.35 & 2000 & 33.12 & 67.14 \\
\hline
\end{tabular}

Notes: (1) ASP displacing fluid. Alkali: $\mathrm{NaOH}, 1.2 \mathrm{wt} \%$; Surfactant: ORS-41, 0.3wt $\%$

(2) Permeability variation factor of cores, 0.72

Table 5 The effect of surfactant concentration on the oil recovery by ASPF flooding

\begin{tabular}{|c|c|c|c|c|c|c|c|}
\hline Test & $\begin{array}{l}\text { Core permeability } \\
\mathrm{mD}\end{array}$ & $\begin{array}{c}\text { Surfactant } \\
\text { concentration, wt } \%\end{array}$ & $\begin{array}{l}\text { Gas-liquid } \\
\text { ratio }\end{array}$ & $\begin{array}{c}\text { Initial oil } \\
\text { saturation } S_{\mathrm{oi}}, \%\end{array}$ & $\begin{array}{l}\text { Oil recovery by } \\
\text { water flooding, \% }\end{array}$ & $\begin{array}{l}\text { Oil recovery by } \\
\text { ASPF flooding, } \%\end{array}$ & $\begin{array}{c}\text { Total oil } \\
\text { recovery, \% }\end{array}$ \\
\hline 1 & 531 & 0.1 & $2: 1$ & 68.5 & 39.1 & 25.3 & 64.4 \\
\hline 2 & 520 & 0.3 & $2: 1$ & 57.6 & 38.8 & 30.3 & 68.1 \\
\hline 3 & 552 & 0.5 & $2: 1$ & 58.8 & 38.4 & 31.0 & 69.4 \\
\hline 4 & 545 & 1.0 & $2: 1$ & 67.8 & 38.8 & 31.2 & 70.0 \\
\hline
\end{tabular}

Notes: (1) ASP displacing fluid. Polymer: 1275A, 1,200 mg/L; Alkali: NaOH, 1.2wt\%

(2) Permeability variation factor of cores, 0.72

\section{Conclusions}

1) Foam has the characteristics of "plugging the water channel rather than flow path for oil", "plugging the macro pores rather than the micro pores" and the gas will rise to displace the residual oil in the top layer, so the ASPF system can significantly control the injection profile, enlarge the swept volume and increase the displacement efficiency.

2) The heterogeneity of the oil strata, the gas-liquid ratio, the concentrations of polymer and surfactant in the ASPF system all significantly influence the oil recovery. Therefore, only the optimized formulation of ASPF system can achieve a better flooding performance.

3) The laboratory experiments show that the ASPF system not only has ultra-low interfacial tension, but also has good foaming performance; therefore, it can greatly enhance the oil recovery ratio, by about $30 \%$ of the original oil in place above that recovered by water flooding.

\section{Acknowledgements}

This paper was financially supported by the Daqing Oilfield Limited Company. The authors are grateful for approval to publish.

\section{References}

Li J, Sui X G and Shao Z B. Microscopic distribution law of remained oil in P1 reservoir of Daqing Oilfield. Petroleum Geology \& Oilfield Development in Daqing. 2005. 24(2): 26-28

Li R F, Yan W, Liu S H, et al. Foam mobility control for surfactant EOR. Paper SPE 1013910 presented at SPE/DOE Symposium on Improved Oil Recovery, Tulsa, Oklahoma, USA, 20-23 April 2008

Li Z Q, Zhou G H and Zhou Z M. The feasibility studies of polymer foam flooding in the Gudao Oilfield. Paper SPE 101189 presented at SPE Asia Pacific Oil \& Gas Conference and Exhibition, Adelaide, Australia, 11-13 September 2006

Liu C L, Yang Q Y, Li B H, et al. Experimental research on sweep efficiency and displacement efficiency of ASP flooding. Petroleum Geology \& Oilfield Development in Daqing. 2007. 26 (2): 108-111

Liu R J, Liu H Q, Li X S, et al. The reservoir suitability studies of nitrogen foam flooding in Shengli Oilfield. Paper SPE 114800 presented at SPE Asia Pacific Oil and Gas Conference and Exhibition, Perth, Australia, 20-22 October 2008

Wang Y P and Cheng J C. The scaling characteristics and adaptability of mechanical recovery during ASP flooding. Journal of Daqing Petroleum Institute. 2003. 27(2): 20-22

Zhao C J, Yao S C, Lu S L, et al. Studies on alkaline/surfactant/polymer combinational foam flood in Daqing. Oilfield Chemistry. 2004. 21(4): 26-28; 357-360

(Edited by Sun Yanhua) 